\title{
船舶配套设备智能化发展战略研究
}

\author{
汤敏, 李沨, 曾力, 华霖 \\ （武汉船用机械有限责任公司，武汉 430084）
}

摘要: 在新一代信息技术与制造业深度融合的产业变革背景下, 推进船舶配套产业智能化转型升级, 对打造有竞争力的船舶 配套品牌产品, 实现造船强国有重要的意义。本文梳理总结国外船舶配套产业发展现状及智能化发展趋势, 分析国内船舶配 套设备智能化发展瓶颈, 提出船舶配套智能化的总体思路、实施路径和顶层架构, 提出船舶配套智能化以需求为导向架构支 撑、以项目为牵引示范引领、开放合作跨界融合的发展推进建议。

关键词: 船舶配套业; 设备智能化; 造船强国

中图分类号: U664.5 文献标识码: A

\section{Intelligent Development of Intelligent Marine Equipment in China}

\author{
Tang Min, Li Feng, Zeng Li, Hua Lin
}

(Wuhan Marine Machinery Plant Co., Ltd., Wuhan 430084, China)

\begin{abstract}
With the deep integration of information technology and the manufacturing industry, intelligent promotion and upgrading now becomes significant for boosting the competitiveness of China's marine equipment industry and for ultimately developing China into a shipbuilding power. The current situation and intelligent development trend of the marine equipment industry in other countries are first summarized in this paper. Bottlenecks that restricts the intelligent development of China's marine equipment is then analyzed. Furthermore, the general idea, implementing approach, and top-level framework are put forward for the intelligent development of China's marine equipment. Moreover, suggestions are proposed for the development, including establishing a reasonable product structure based on demand, promoting the demonstrating and guiding role of major projects, and enhancing cooperation among different industries.
\end{abstract}

Keywords: marine equipment industry; equipment intelligentization; shipbuilding powerhouse

\section{一、前言}

船舶配套设备作为海洋工程及高技术船舶的重 要组成部分, 具有量大、面广和高技术、高附加值 的产业特点, 按大类分主要包括机电配套设备、船
舶动力系统和电气自动化系统等。“十一五” 以来, 政府和行业开始加大自主产品的研发投入, 行业得 到了快速发展, 产业体系不断完善, 重点船用设备 及核心部件研制取得了突破, 产业规模大幅提升, 本土配套设备装船能力不断提高。但与发达国家相

收稿日期 : 2019-10-03; 修回日期 : 2019-10-09

通讯作者: 汤敏, 武汉船用机械有限责任公司研究员级高级工程师, 研究方向为船舶与海洋工程; E-mail: tangmin@wmmp.com.cn 资助项目：中国工程院咨询项目 “海洋强国战略研究 2035”(2018-ZD-08)

本刊网址 : www.engineering.org.cn/ch/journal/sscae 
比, 船用设备仍存在产业链不完善、设计研发能力 薄弱、高端配套几乎被国外知名品牌垄断、生产效 率和产品可靠性与国际一流品牌产品有很大差距、 产品服务能力不足等问题, 配套设备发展滞后问题 已成为制约造船强国建设的主要瓶颈。

在当前全球制造业格局面临重大调整、我国 经济发展环境发生重大变化的背景下, 新一代信息 技术与制造业深度融合的产业变革正在引发深远影 响, 以 “互联网 + 先进制造业” 为核心的海洋工程 装备及高技术船舶信息技术革命已成为国家造船业 转型升级、建设制造强国的重要发展方向。船舶配 套产业亟需通过设备智能化能力提升, 打造有竞争 力的品牌产品, 形成技术、品牌和产业链生态优势, 全面提升产业的研发设计、核心制造、全球服务水 平, 推动船舶配套产业转型升级, 实现造船强国的 战略目标。

\section{二、国外船舶配套设备产业现状及未来智能 化发展趋势}

\section{（一）国外船舶配套设备产业现状}

从国际配套产业发展趋势看, 以欧洲、日本、 韩国为主的国外配套产业在产品技术研发能力、产 品质量和售后服务能力等方面占据明显优势。近年 来, 随着世界船舶制造中心向亚太地区转移, 日本、 韩国、欧洲纷纷针对我国造船业的发展制定了相应 的船舶配套发展战略, 逐步由技术转让、合资合作 转为在中国独资建厂或向中国出口产品或抬高技术 引进门槛从而提高合资的控股比例, 同时在售后服 务环节不但为本国企业品牌产品也为其他企业品牌 产品承担全球服务业务, 我国船舶配套业发展面临 着前所未有的技术来源紧缩的不利形势 [1]。

\section{1. 欧洲船舶配套设备产业现状}

欧洲作为造船业的发源地, 配套业起步早, 历 史悠久, 其历经了多次技术革命, 形成了享誉全球 的品牌, 拥有着强大的品牌效应。在数百年的研发 历程中, 始终重视产品先进性、可靠性和稳定性, 通过持续技术研发和产品优化, 保持着配套设备的 高附加值, 长期引领着先进配套设备技术。同时, 欧洲船舶配套企业依托自身强大的实力, 形成了遍 布全球的售后服务网络, 在世界范围内提供便利的 维修和升级服务, 致力提供产品全生命周期解决方
案。此外, 欧洲主要配套企业通过跨国集团战略合 作、形成技术合力，争夺着世界各国配套市场。

2. 日本船舶配套设备产业现状

日本是船舶工业中的后起之秀, 自 20 世纪 50 年 代成为世界造船大国以来, 以造船需求拉动着配套 业迅速发展，通过技术引进、技术合作、研发资金 储备等方式, 促使船舶配套业实现了规模快速扩 张。在产业发展期, 日本建立了相辅相成的船舶配 套业管理体系, 政府、行业组织和企业有效分工, 按不同专业分工形成集中优势, 规避了企业间的不 良竞争, 并通过加强技术创新, 逐步建立了品种齐 全、体系完整、规模庞大的产业体系。现今, 日本 以稳定的供应系统、高效精益的生产管理模式满足 着 $95 \%$ 以上的本土配套装船率 [2], 并实现大量向 国外出口，同时借鉴欧洲的经验，在售后服务方面 建立了完善的全球服务体系, 并致力于使产品开发、 应用与市场需求变化同步。

3. 韩国船舶配套设备产业现状

自 20 世纪 80 年代以来, 韩国在政府引导下, 积极推进船用设备保护政策, 通过限制船舶配套产 品进口、协调船厂配套、加强欧洲与日本技术合作 引进等方式, 逐步建立比较完善的船舶配套体系, 使得配套企业技术水平迅速居于先进行列, 本土 化率达 $85 \%$ 。同时, 韩国鼓励加强与国外著名公 司的合作, 致力提升产品核心竞争力和在世界范 围的品牌影响力。

综上, 国外领先的船舶配套企业以其强大的技 术研发能力、精益制造能力和全球化的售后服务能 力, 构建了规模庞大、高质量、竞争力强的产品体 系, 并通过高精企业间产业链协同合作, 始终占据 着高端配套行业市场，引领行业发展。

\section{（二）国外船舶配套设备智能化发展趋势}

随着现代科学技术的发展, 以互联网信息化、 大数据分析、人工智能为代表的新一轮技术的高速 发展正迅速、深刻地影响着所有产业, 全球工业正 朝着信息化、智能化的方向迈进。对于船舶工业而 言, 随着网络技术和信息技术的广泛应用, 船舶自 动化机电设备、动力设备以及通信导航等电气系统 也正朝着分布型、网络型和智能型的方向发展 [3], 在智能化配套设备支撑下的智能船舶发展成为大势 所趋。 
近年来, 国际海事组织 (IMO)、国际标准化 组织 (ISO) 等国际机构已将智能船舶列为重要议题。 IMO 主推的 “E-navigation” 战略也是以船舶智能 化作为支撑, 相关技术规则与标准日渐明晰, 国际 方面包括中国船级社已设定清晰的规范指南, 并设 立特定的智能船符号。世界主要造船国家正快速推 进船舶智能化进程, 竞相研制各类智能船舶及相关 系统和设备。

现今, 随着自动化技术和信息技术日趋成熟, 船舶动力系统和电力系统信息化水平较高, 基本实 现了数字化控制, 如电力系统已实现智能监控和能 效管理; 动力系统可实现主机、推进器等核心动力 设备的状态监控, 部分船型可实现协同控制。然而, 船舶配套设备种类繁多, 技术覆盖面广, 技术水平 差异大, 因此配套设备的数字化、网络化、智能化 程度参差不齐, 有些设备仍依赖人力操作, 无自动 化能力; 有的设备通过人工下达控制指令, 初步实 现了数字化; 有的设备具备一定的自主分析决策能 力, 具备智能化功能。可以说, 中国与世界造船发 达国家在船用机电设备智能化研究领域基本处于同 一起跑线, 谁先突破配套设备智能化关键技术, 打 造有竞争力的智能化配套设备, 谁就能抢占新局势 下的智能船舶配套市场。

在智能船舶新一轮技术革命的冲击下, 国际领 先的船舶配套公司已经着手与自动化控制公司进行 强强联合, 力图打造新一代智能船舶生态体系, 成 为向未来海事行业提供解决方案的重要战略供应 商, 争夺智能船舶配套市场。例如, 2018 年 7 月, 罗尔斯罗伊斯公司 (Rolls-Royce) 将旗下的商用船 舶业务向康士伯集团出售, 包括船用配套（推进系 统、甲板机械、自动控制系统等)、船舶远程健康 管理系统船舶设计和售后服务业务, 此次合并意味 着智能船舶领域新巨头的诞生。

\section{三、国内配套设备产业现状及智能化发展 需求}

\section{（一）国内船舶配套设备产业现状}

近年来, 我国造船业发展迅速, 已多年位居世 界第三, 且世界十大顶级船企中国占两席, 中国船 舶总装建造的世界影响力越来越大。然而, 国内船 舶配套企业在世界知名船舶配套企业排名中却名落
孙山，船舶配套设备国产化率为 30\% 40\%，甚至 某型高技术船舶自主配套率不足 5\% [4], 制约着我 国造船工业的高速发展。

1. 核心配套体系不健全, 战略引领不足

从产品分布特点和产业链布局来看, 我国船舶 配套业生产的产品包括甲板机械部分产品、舱室机 械少部分产品、动力装置产品和大部分舾装件, 在 自动化系统 (动力定位)、船舶舱盖等高技术产品方 面被国外少数品牌垄断, 甲板机械的高压洜、高精度 液压伺服控制阀等核心元件还依赖进口。同时, 国内 配套企业呈现规模小、数量多、配套产业集成度不 高、规模效应不明显等问题, 例如中国共有 11 家船 用低速机制造企业, 产品处于同质化竞争格局, 企业 在高压竞争下一直为生存和规模焦虑, 缺乏一以贯 之的发展战略规划和持之以恒的做专做精精神, 盲 目的低水平的竞争状况验证, 企业市场竞争力不强。

2. 研发投入不足, 技术积累不够

受制于行业前景及企业效益等多方原因, 我国 船舶配套产品体系和技术体系还不够完备, 创新模 式仍属追随型, 对新技术的研发投入不够, 海洋工 程装备和高技术船舶配套设备占比明显低于日本和 韩国, 特别是在深水装备方面差距更为明显。同时, 在产品交付后的跟踪机制也不健全, 新产品研发和 传统产品迭代升级周期长, 面向研发知识的积累机 制不健全, 且技术团队不稳定, 缺乏有力的持续发 展动力。

\section{3. 工程整体解决能力不足, 产品竞争力不强}

国内船舶配套企业注重产品研发而不太关注制 造、安装、应用、维护等工程技术研究, 专业化制 造能力和精细化管理水平与国外行业差距明显。例 如, 在配套设备研制过程中基本不具备产品质量追 溯能力, 一旦出现因装配导致的质量问题, 后续对 设备的维修成本极高, 影响企业运营成本、生产效 率、产品不良品率等一系列指标, 难以建立产品的 品牌效应。

\section{4. 产品服务能力不足, 运维成本高}

国内企业服务意识薄弱, 全球服务网络不健全, 服务对产业的回馈不够。此外, 国内船舶配套产品 在故障诊断、监测与服务保障技术方面, 相关的技 术研究和应用成果比较单薄, 整体应用的基础环境 非常欠缺。机电设备随船运行, 离岸基本无法维修, 维修只能进坞进行, 导致时间损失及成本损失巨大, 
在这样的维保过程中，配套设备故障的修复时间长、 售后效率低等问题就无法避免。

\section{（二）国内船舶配套设备智能化发展需求}

对标国外船舶配套产业致力提升智能化产品技 术研发能力、精益制造能力和全球化的售后服务能 力的发展趋势, 结合我国配套产业发展现状, 国内 船舶配套亟需通过智能化技术应用, 解决产品质量 及技术积累问题，保障产品一次交付成功、产品可 靠性高; 解决产品核心竞争力不足问题, 降低产品 设计成本、制造周期，提高维护效率; 满足新规范 要求下绿色、安全、环保的需求; 减轻国内劳动力 瓶颈, 减少设备制造人员和人工成本; 降低设备运 营成本压力, 研制少人化、低能耗、高效率的设备; 满足新形势下高端、个性化的需求, 提供设备集成、 安装交付和运维保障服务整体解决方案, 最终提升 产品质量和竞争力, 推动船舶配套产业转型升级, 实现造船强国的战略目标。

\section{四、配套设备智能化发展对策及展望}

\section{（一）总体思路}

按照《中国制造 2025》对海洋工程与高技术船 舶在 2025 年实现船舶工业制造强国的要求, 围绕
高技术船舶和海洋工程装备技术规范和行业发展需 要, 面向船舶设备行业需求和特点, 以全面数字化、 核心智能化为抓手, 以补齐产业短板、推动设备智 能化升级为总体目标, 整体规划、分步实施, 打造 有竞争力的品牌产品, 形成技术、品牌和产业链生 态优势，全面提升产业的研发设计、核心制造以及 全球服务水平。

\section{（二）实施路径}

围绕船舶配套设备自主设计、集成配套、核 心制造和全生命周期服务的需要，以突破智能化 关键技术、打造智能化制造和智能化产品为主线, 整合产业链优势资源，分步实施，逐步提升产品 的研发能力、制造能力、服务能力的智能化水平, 借鉴亚琛工业大学对工业 4.0 发展路径的研究成 果, 实施路径如图 1 所示。率先实现船舶配套的 数字化, 在产品研制过程中建立集成互联的信息 化系统, 实现产品远程监控; 在数字化基础上实 现船舶配套网络化, 建立透明化、可视化和基于 数据决策产品制造和管理环境, 实现产品远程操 控、数据辅助决策和优化; 在数字化、网络化基 础上实现船舶配套智能化, 实现智能制造系统的 预测和自适应优化, 实现设备无人操作、自适应 控制和自主维护。

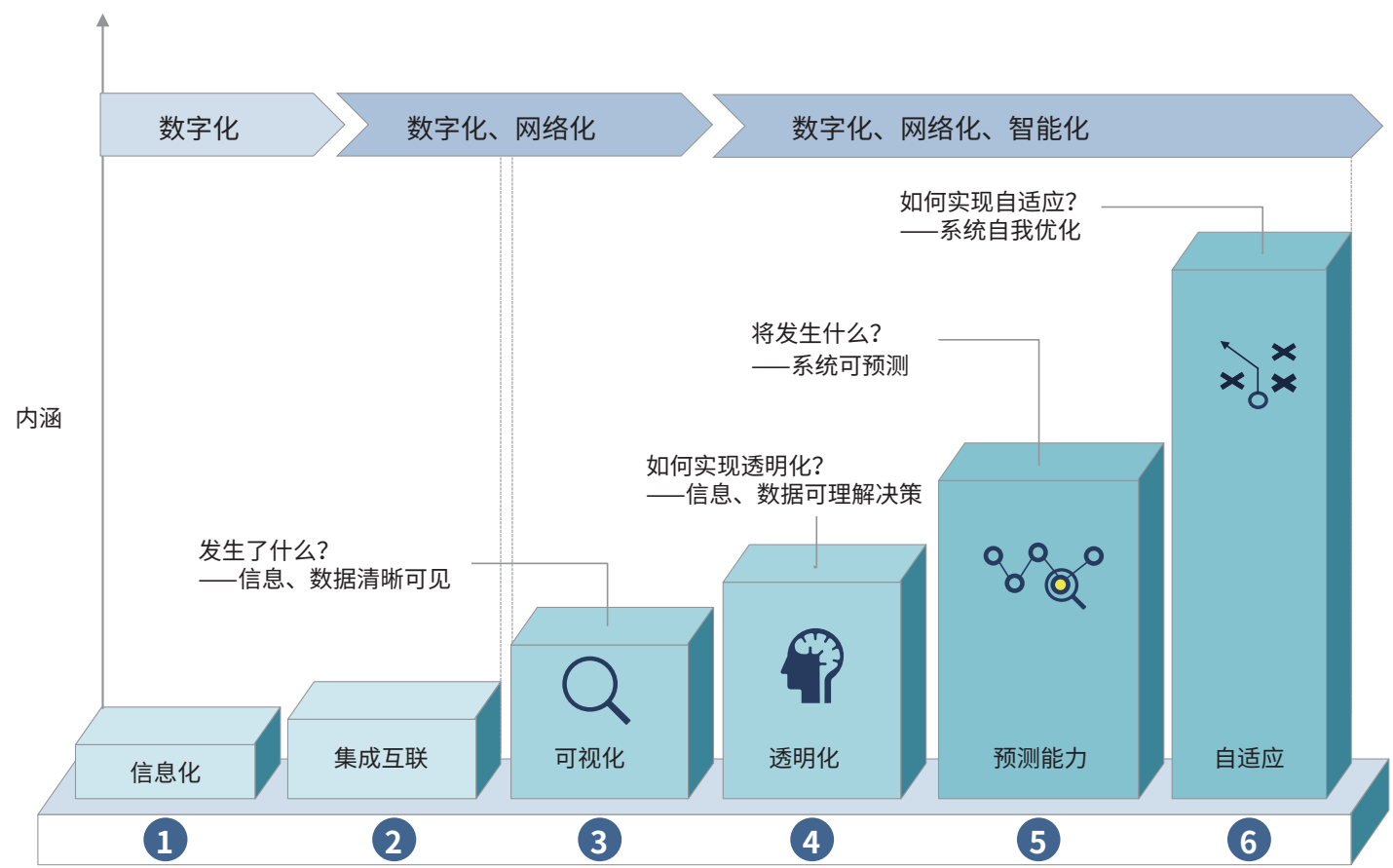

图 1 船舶配套设备智能化实施路径 


\section{（三）顶层架构}

针对船舶配套设备的离散制造产业特点, 建立 “1 个集成环境 +3 个重点方向” 的数字工厂顶层架 构，如图 2 所示。“1 个集成环境”指围绕企业核心 管理和决策建立智能化集成环境、数据体系和基础 环境, “3 个重点方向” 指面向产品研发、制造和服 务过程, 建立智能化虚拟设计环境、智能化精益生 产环境和智能化产品数字孪生环境, 构建产品全生 命周期过程产业基石，并基于蓝图逐步实现。

\section{（四）发展建议}

按照制造强国战略部署, 围绕自主设计、集成 配套、核心制造和全生命周期服务需要, 聚焦产业 发展战略定位, 通过先进的智能制造技术, 大幅提 升产业能力, 加快推进我国船舶配套高质量发展进 程, 具体发展建议如下:

1. 项目牵引, 示范引领

以国家科研计划为强力牵引, 围绕项目实施、
监控、评价与改进全过程, 强化科研项目的示范性 和带动性, 强化项目对产业的示范引领作用, 不能 唯项目论。

\section{2. 需求第一, 架构第一}

开展需求研究, 以需求为导向, 实现多领域 融合 (船船、船港、船岸等)、多设备融合, 提供 整体解决方案, 提升协同效率。同时建立合理科 学的产品架构 (产品平台化、功能模块化、系统 集成化), 基于去中心化的思路, 才能更灵活地适 应市场需要。

\section{3. 开放合作, 跨界融合}

鼓励行业内外开放, 在跨界融合模式下推进 产品创新、品牌合作和市场营销合作, 借助开放 合作的力量, 获取更多的资源, 形成更大的优势。 在新需求的驱动下, 以新科技和新平台为依托, 将现有产业领域和要素资源, 经过相互渗透、融 合或裂变, 整合利用到一起, 实现产业价值链的 延伸或突破。

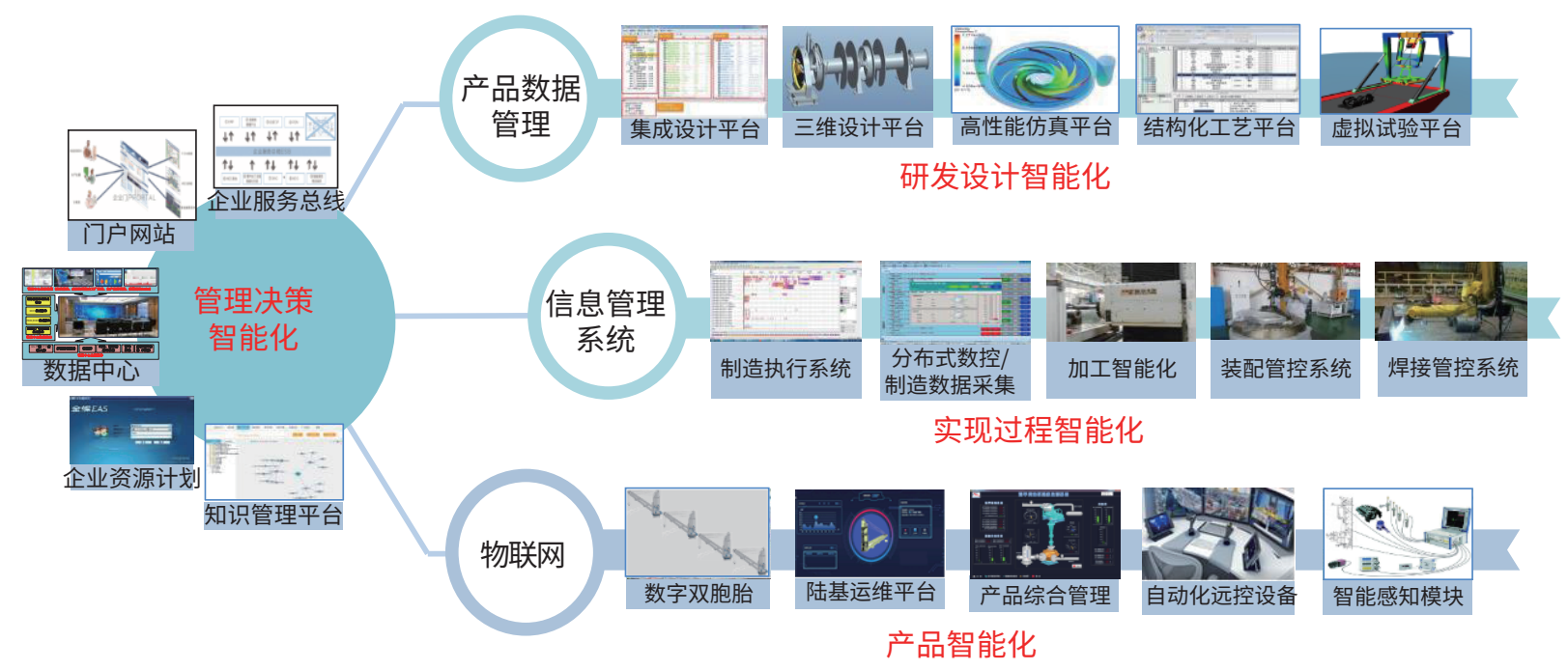

图 2 船舶配套设备智能化顶层架构

\section{参考文献}

[1] 刘圣勇. 中外船舶配套产业发展现状分析 [J]. 商业经济, 2012 (12): 74-75.

Liu S Y. Status analysis of marine equipment industry at home and abroad [J]. Business Economy, 2012 (12): 74-75.

[2] 李成强. 日本船舶配套产业现状与发展路径分析 [J]. 船舶物资 与市场, 2010 (3): 27-30.

Li C Q. Analysis on the current situation and development of marine equipment industry in Japan [J]. Marine Equipment/Materials \& Marketing, 2010 (3): 27-30.
[3] 刘微, 尚家发. 智能船舶发展现状及我国发展策略研究 [J]. 舰 船科学技术, 2017 (11): 189-193.

Liu W, Shang J F. Research on the development status of intelligent ship and the development strategy of China [J]. Ship Science and Technology, 2017 (11): 189-193.

[4] 富贵根, 蒋原成, 桂文彬, 等. 船舶辅机技术的发展与创新 [J]. 上 海造船, 2007 (1): 29-31.

Fu G G, Jiang Y C, Gui W B, et al. Development and innovation of marine auxiliary technology [J]. Shanghai Shipbuilding, 2007 (1): 29-31. 